\title{
Retos y compromisos gremiales en el marco de la pandemia por COVID-19
}

\author{
Flor Esperanza Rodríguez Ferro'
}

Rodríguez-Ferro, F.E. Retos y compromisos gremiales en el marco de la pandemia por COVID-19. Revista Ocupación Humana, 20 (1), 4-6. https://doi.org/10.25214/25907816.945

A través del tiempo, la Revista Ocupación Humana se ha ido constituyendo en un referente de la difusión del conocimiento de la Terapia Ocupacional colombiana y latinoamericana. Diferentes autores han buscado exaltar, a través de sus páginas, el valor de la ocupación y de nuestro desempeño profesional en diferentes contextos, mediante la publicación de artículos originales e inéditos que surten exigentes procesos editoriales. Así mismo, la Revista se ha ido posicionando en la comunidad profesional y estudiantil nacional e internacional, no solo como un medio de consulta, sino como un puente que posibilita la interacción con asuntos relevantes en el campo de la ocupación humana.

Una situación particular enmarca este número y también acompaña al nuevo Consejo Directivo Nacional del Colegio Colombiano de Terapia Ocupacional: la pandemia por COVID-19. Al respecto, la Comisión Municipal de Salud de Wuhan (provincia de Hubei, China) notificó en diciembre del 2019 de un conglomerado de casos de neumonía en la ciudad; posteriormente se determinaría que eran causados por un nuevo coronavirus. El 5 de enero de 2020, la Organización Mundial de la Salud -OMS publicó su primer parte sobre brotes epidémicos del nuevo virus, una publicación técnica de referencia para la comunidad científica y de salud pública mundial, y para los medios de comunicación. Dicho informe contiene una evaluación del riesgo y una serie de recomendaciones, así como la información proporcionada por China a la Organización sobre la situación de las

1 Terapeuta ocupacional. Magíster en Discapacidad e Inclusión Social. Magíster en Educación. Presidenta del Consejo Directivo Nacional 2020-2022, Colegio Colombiano de Terapia Ocupacional. Bogotá, Colombia. presidencia@tocolombia.org iD https://orcid.org/0000-0002-2093-4164 
y los pacientes y la respuesta de salud pública ante los casos de Wuhan (OMS, 2020). Desde entonces, nuevos retos, dinámicas ocupacionales, modificaciones en los hábitos y rutinas han venido acompañando a la humanidad en su desempeño ocupacional.

En relación con lo anterior, los cambios generados han implicado que incluso las formas de administración y de empalme frente a diferentes actividades, como las desarrolladas por el Consejo Directivo saliente, se hayan visto impactadas. Esfuerzos valiosos y únicos marcan no solo una entrega, sino, aún más importante, los nuevos retos y compromisos gremiales que han implicado al nuevo Consejo generar acciones y respuestas inmediatas frente a la pandemia, a la comunidad profesional y a los diferentes escenarios laborales. Aun así, tales dinámicas se han convertido en una oportunidad para mostrar, con mayor fortaleza, nuestra razón de ser como terapeutas ocupacionales en una sociedad ávida de respuestas frente a esta situación desconocida que ha transformado la vida de todas las personas.

En este orden de ideas, es claro que las acciones profesionales de la Terapia Ocupacional no pueden seguir siendo las mismas en tiempos de pandemia y pospandemia, como nuevos momentos históricos. Al respecto, perspectivas enfocadas en el mayor uso de la virtualidad; en el trabajo y la rehabilitación en casa; en la telesalud y la telerrehabilitación, y en los diferentes apoyos generados según el curso de vida de las poblaciones, marcan nuevos derroteros para la profesión y para la evidencia que será necesario consolidar mediante la participación activa de la comunidad, que con sus investigaciones, experiencias y construcciones, posibilitará horizontes novedosos para nuestra Revista.

Como Consejo Directivo 2020-2022, la potencialización y el reconocimiento de estas nuevas experiencias será también, en adelante, un derrotero; más aún cuando implica y nos exige construir, escribir y generar sobre algo para lo que nadie estaba preparado. Nos invita a seguir proyectando espacios de encuentros y desencuentros, de aciertos y desaciertos donde no existe el saber absoluto y en los que el Plan de Acción 2016-2026 seguirá siendo nuestra guía, claro está, con reformulaciones, reflexiones y acciones pertinentes para el periodo de esta administración. De allí la importancia de monitorear y tener claridad sobre los impactos que la pandemia genere para nuestra profesión, para nuestro gremio y para el Colegio mismo; de tener presente que los procesos de calidad nos exigen apuntarle a consolidar durante este periodo el mayor número de procesos y procedimientos que nos posicionen como una organización con altos estándares en la gestión, y que la bioseguridad toma un rol protagónico en todos los escenarios del desempeño ocupacional.

Para esto, el trabajo conjunto con los equipos de trabajo, comités y delegaciones del Colegio Colombiano de Terapia Ocupacional ante los diferentes espacios de representación, concertación y discusión nos seguirá llevando a escenarios que posibiliten un creciente reconocimiento profesional y gremial. Esto se acompaña de acciones proyectadas para lograr la mayor democratización posible del Colegio, con un claro posicionamiento regional en el que los cuerpos directivos tienen un camino importante en materia de consolidación gremial. Para el Consejo Directivo resulta claro que 
lograr la sostenibilidad, aspecto crítico en gran parte de las instituciones y organizaciones del país, requiere de nuevas estrategias que impacten la toma de conciencia sobre la responsabilidad que implican nuestras acciones en el escenario de la prestación de servicios y se acompañen de nuestra fuerza y capacidad como gremio.

Para que todo esto sea posible son importantes las acciones en educación continuada, donde se buscará reconocer y rescatar esos diversos saberes y experiencias, muchas veces individuales y ocultos, que merecen hacer parte del conocimiento disciplinar. A esto se suman las exigencias que marcan el actuar de los colegios profesionales y la capacidad de respuesta frente a los diferentes actores del Sistema General de Seguridad Social en Salud. De estas acciones surgirán nuevos escenarios de construcción y socialización de espacios formativos que, en estos momentos, nos retan a desarrollar competencias donde las tecnologías de la infomación y las telecomunicaciones, la virtualidad y las capacidades de investigación adquieren mayor relevancia.

Relacionado con lo anterior, difícilmente una organización puede hacer todo lo que sueña sin que sus comunicaciones impacten en las redes sociales y en las comunidades virtuales, aquellas que cada día surgen y se transforman en el contexto global. Así, partiendo de las acciones ya realizadas y motivada por el interés, la calidad y el amor de quienes nos antecedieron, expreso en nombre del Consejo Directivo Nacional nuestro agradecimiento. Lo hecho es motivo de impulso para seguir adelante $y$, ante todo, para responder a las dinámicas sociales, comunicativas, gremiales, políticas y de la prestación de servicios que tampoco seguirán siendo las mismas. Como precisan nuestras colegas argentinas:

El contexto actual exige la participación activa como agentes sociales, co-construyendo redes en la comunidad en pos de la defensa de los derechos de todas las personas a tener un trabajo digno, acceso a la salud, educación y vivienda. Al mismo tiempo, la tarea de registrar, sistematizar y reflexionar sobre las experiencias, los modos de intervenir y observar la forma en que las personas se relacionan entre sí, con las cosas y con la ocupación nos permitirá contribuir al desarrollo de conocimiento. Las investigaciones situadas y contextualizadas que respondan a las necesidades locales y visibilicen la práctica profesional harán valiosos aportes a la disciplina. (Albino et al., 2020, p.4)

\section{Referencias}

Albino, A.F., Acuña, C.Y., Carroli, B., Ciampa, M.A., Olarte, M.F. y Andrade, M. (2020). Desafíos en tiempos de pandemia. Revista Argentina de Terapia Ocupacional, 6(2), 3-5. http://www.revista.terapia-ocupacional.org.ar/RATO/2020jun-edit.pdf
Organización Mundial de la Salud [OMS] (2020, 27 de abril). COVID-19: cronología de la actuación de la OMS. OMS. https://www.who.int/es/news-room/detail/27-04-2020-who-timeline---covid-19 